\title{
Rule Based Reasoning Method for Safety Room by Means of Temperature Sensor and Motion Detector
}

\author{
Mufadhol, ${ }^{\mathrm{a}, *}$ Guruh Aryotejo, ${ }^{\mathrm{b}}$ and Daniel Yeri Kristiyanto ${ }^{\mathrm{c}}$ \\ ${ }^{\mathrm{a}}$ Departement of Computer System, ${ }^{\mathrm{b}}$ Informatic Management, ${ }^{\mathrm{c}}$ Information System and ${ }^{\mathrm{a}, \mathrm{b}, \mathrm{c}}$ Researcher Laboratory, \\ STEKOM Semarang, Jl. Majapahit 605 Pedurungan Semarang, Indonesia \\ *Corresponding author,Email: amasyong29@gmail.com, ${ }^{\text {b } g u r u h 2000 @ y a h o o . c o m, ~}{ }^{c}$ stekom.jerry@gmail.com \\ *Corresponding author Email: masyong29@gmail.com
}

\begin{abstract}
Theft and infiltration as well as robbery are an incident that should be anticipated. The security of the room is a main priority to prevent such occurrences. This paper will be explain how to the rule based reasoning method is part of the expert system that can be used in a security room systems by monitoring the temperature change in the room as well as detecting movement in the room by using the temperature sensor and motion detector. The output indicators is the buzzer sounds that will be activated when there is an increase in the temperature and/or there is a movement in the room.
\end{abstract}

Keywords: Rule based, temperature, motion detector, safety room.

\section{Introduction}

Recently, the development of software engineering is heavily influenced by the advancement of science and technology. Human, unconsciously, is heading into a new era that is called digital era. The existence of software is highly required in this digital era. Software engineering can be used to support human life, such as utilization of rule based reasoning method for room security. Human needs in securing a room is increasing due to changes in the more effective and efficient security patterns. ${ }^{1}$ There are a lot of ways to secure a room againts theft and infiltration as well as robbery. ${ }^{2-4}$ One of them is to use a rule based reasoning method. ${ }^{5}$ Combined with the use of a temperature sensor, ${ }^{6,7}$ and/or motion detector. ${ }^{8-10}$ The utilization of rule based reasoning method, which is a part of an expert system, ${ }^{11}$ in artificial intelligence can be used to improve room security. ${ }^{1,2}$ Expert System is a computer program developed for a particular field that can solve a problem and find a solution that is comparable to an expert in that same field. ${ }^{12,13}$ Development of expert system require knowledge extraction or acquisition of knowledge and the role of an expert in that particular field is still needed. ${ }^{11,14}$ Finding a solution in order to solve a problem by giving priority to a rule is a main characteristic of a rule based reasoning method..$^{5,13}$ 


\section{Research Method}

Rule based reasoning method, which is a part of an expert system, is based from elements of syntax and symantec. These will be materialized in the form of program instruction which in turn will be executed to become machine language that will be a control center for ATmega328 Microcontroller. The inference engine that utilize forward chaining is used on rule based reasoning method, ${ }^{12}$ to control a LM35DZ as temperature sensor signal and/or PIR sensor to detect a motion to trigger a buzzer in order to solving a room security issue. ${ }^{5,6}$ This method can be seen in the Figure 1.

Microcontroller is a multipurpose IC (integrated circuit) that can be programmed. ${ }^{15,16}$ Arduino Uno is a microcontroller board based on the ATmega328. ${ }^{17}$ The programming in ATmega328 IC is using Arduino Integrated Development Environment (IDE) named Sketch in the form of instruction. ${ }^{18}$ ATmega328 microcontroller has 14 digital input/output pins, $16 \mathrm{MHz}$ ceramic resonator, 6 analog inputs, USB connection, power jack, ICSP header, and reset button. ${ }^{19}$

LM35DZ is a temperature sensor in the form of integrated circuit (IC) that have an output voltage that linearly proportional to the Celsius (Centigrade) temperature and can detect temperature between $-55^{\circ} \mathrm{C}$ to $150^{\circ} \mathrm{C} \cdot{ }^{6-7} \mathrm{LM} 35 \mathrm{DZ}$ can convert temperature to voltage with a sensitivity of $10 \mathrm{mV} /{ }^{0} \mathrm{C} .{ }^{20} \mathrm{LM} 35 \mathrm{DZ}$ can be controlled by applying a $+5 \mathrm{v}$ voltage on pin 1 . Pin 2 is an output and pin 3 act as a ground. ${ }^{6-7,20}$

Passive Infrared Receiver (PIR) responds only to incoming infrared radiation that emitted from every object, especially the human body. ${ }^{10}$ Infra Red (IR) filter in the PIR is able to detect IR wavelength between 8-14 micrometers, while human body radiate IR at wavelengths of 9-10 micrometers. ${ }^{8,9}$ PIR will not produce any output if an object passing the PIR sensor does not have a IR wavelength between 8-14 micrometers. These IR wavelengths only emitted from a hot object, like a very bright lamp light that is able to produce heat, object reflection from the mirror and hot summer temperature.

\section{Results and Discussion}

\section{A. Knowledge based}

Information gathering, and to do observations, is the first step in solving a room security problems. The objective is to build a room security system that is able to secure the room from theft, infiltration and robbery. Layout design and validation testing for security tools are always consulted with an expert. Improvement and correction for a room security system will be conducted under supervision of an expert. When an expert declared the system is perfect, then it will be put into use.

\section{B. Design Rule Based and Architecture of the System}

The system works by using a PIR sensor and a temperature sensor. PIR sensor, which have the maximum detection range about 20 feet ( 6 meters), ${ }^{10}$ will be act as an active motion detector. It will be triggering a buzzer if a human presence is detected. Second sensor, a temperature 
sensor, is set between $0^{\circ} \mathrm{C}$ to $31^{\circ} \mathrm{C} .{ }^{6,20}$ Buzzer will be activated when a temperature sensor detect a room temperature is above $31^{\circ} \mathrm{C}$. The basic principles of this security system is as an electronic access control using motion detector by means of PIR sensor and LM35DZ temperature sensor. This system will automatically detect the room temperature and will trigger the buzzer if the temperature in the room is increasing. Buzzer also will be triggered if a PIR sensor activated and detected a movement in the room. The enforcement of this rule can be seen in the program embedded in the ATmega328 microcontroller chipset.

\section{Inference Engine Technique}

Inference engine have a role as a controller for expert system. It have a function to guide a reasoning process to become a process that manipulate and direct a rule, model and fact, which are stored in the knowledge base in order to solve a problem or a conclusion. In the process, inference engine use a reasoning strategy by using a list of rules based on sequence and pattern, ${ }^{5}$, 11-14 as shown in the flowchart on Figure 2. In this system, a power supply circuit must be able to deliver a stable electric current to microprocessor in order to prevent voltage drop during operation. This same circuit also serves as a AC to DC converter and to providing the right voltages for an electronic circuit, which are $5 \mathrm{v}$ and $12 \mathrm{v}$. $5 \mathrm{v}$ voltage is used on ATmega328 microcontroller, motion detector PIR sensor and temperature sensor. $12 \mathrm{v}$ voltage is used to charge a battery as a backup power source.

\section{System Validation}

System testing using rule based reasoning method can be done by individual validator or potential user for software engineering for room security system. The first phase of testing is to verify system design or to validate security system design. The second phase is testing the security system by potential user. Testing and validation process are done using questionare in the form of validator form. This validator form contains grading value which is assessed from some indicators by choosing according to criteria. The final score determine whether the design of security system has fulfilled potential users requirement or needs further revisions.

\section{Conclusion}

The room used as a place to store archives, files and some other valuable goods needs some kind of security measures. This can be done automatically by utilizes an expert system and rule based reasoning method, to control LM35DZ temperature sensor, Motion Detector PIR Sensor and Atmega328 microcontroller. This combination can optimally improve the room security .

\section{Acknowledgments}

The authors thank to Prof. Drs. Mustafid, M.Eng., Ph.D. and Dr. Suryono, S.Si., M.Si. from Master Program of Information System, School of Postgraduate Studies, Diponegoro University, Semarang, Indonesia, for the referral, guidance and cooperation. Dr. Ir. Agus Wibowo, S.Th., M.Si., M.M., M.Kom. as director of STEKOM Semarang, Indonesia, for all facilities and amenities. 


\section{References and Notes}

1. G. Marek, S. Peter. Design The Robot as Security System in The Home. Procedia Engineering 96 in Modelling of Mechanical and Mechatronic System. IEEE, page: 126-130. (2014).

2. J. V. Lee, Y. D. Chuah and C. T. Chai. A Multi Level Home Security System (MHSS). International Journal of Smart Home. Vol.7, No.2, page: 49-60. (2013).

3. J. Bangali, and A. Shaligram. Design and Implementation of Security Systems for Smart Home Based on GSM Technology. International Journal of Smart Home. Vol.7, No.6, page: 201-208. (2013).

4. S. Budijono, J. Andrianto and N. Noor. Design and Implementation of Modular Home Security System with Short Messaging System. EPJ Web of Conferences 68. EDP Sciences, page: 1-5. (2014).

5. B. Koo, Y. S. Park, and S. H. Yang. Microcontroller Implementation of Rule-based Inference System for Smart Home. International Journal of Smart Home. Vol.8, No.6, page: 197-204. (2014).

6. Navya, G. Dumala. Web Based Automated Smart House Management. TELKOMNIKA Indonesian Journal of Electrical Engineering. Vol.13, No.3, page 493-496. (2015).

7. Poonam, Y. Molge. Remote Temperature Monitoring Using LM35 Sensor and Intimate Android User via C2DM Service. International Journal of Computer Science and Mobile Computing. Vol.2, Issue.6, page: 32-36. (2013).

8. N. L. Ramli, et al. Implementation of Passive Infrared Sensor in Street Lighting Automation System. ARPN International Journal of Engineering and Applied Sciences. Vol.10, No.22, page: 17120-17126. (2015).

9. N. Y. Reddy, K. Sridevi. Passive Infrared (PIR) Sensor Based Security System Using PSOC. Internetional Journal \& Magazine of Engineering, Technology, Management and Research. Vol.1, Issue.12, page: 804-807. (2014).

10. M. Sathishkumar, S. Rajini, Smart Surveillance System Using PIR Sensor Network and GSM. International Journal of Advanced Research in Computer Engineering \& Technology. Vol.4, Issue.1, page: 70-74. (2015).

11. C. F. Tan, et al. The Application of Expert System: A Review of Research and Application. ARPN International Journal of Engineering and Applied Sciences. Vol.11, No.4, page: 2448-2453. (2016).

12. M. Negnevitsky. Artificial Intelligence: A Guide to Intelligent Systems. 3rd Edition. Addison Wesley. Pearson Education. UK. (2011).

13. J. P. Ignizo. Introduction to Expert System : The Development and Implementation of Rules Bases Expert System. Mc Graw-Hill. New York. USA. (1991).

14. J. Giarratano and R. Gary. Expert System : Principle and Programming. 4th ed. Jennifer Smith Jennifer Harvey. Course Technology. Massachusetts. Boston. (2005). 
15. M. M. Ali, et al. Microcontroller Application in Industrial Control and Monitoring Systems. International Journal of Engineering trends and Technology. Vol.17, No.1; page: 26-31. (2014).

16. E. Theophilus. Development of Microcontroller Base Automatic Level of Discomfort Index Measurement using Thom Model. ARPN International Journal of Science and Technology. Vol.2, No.7, page: 158-165. (2012).

17. R. H. Sudhan, et al. Arduino Atmega-328 Microcontroller. International Journal of Innovative in Electrical, Electronics, Instrumentation and Control Engineering. Vol.3, Issue.4, page 27-29. (2015).

18. S. V. Devika, et al. Arduino Based Automatic Plant Watering System. International Journal of Advanced Research in Computer Science and Software Engineering. Vol.4, Issue.10, page: 449-456. (2014).

19. S. R. Prabha, et al. Smart Electric Fan System Using Arduino Atmega328. International Journal of Innovative Research in Technology. Vol.1, Issue.10, page: 26-28. (2014).

20. M. S. Chavan, et al. AVR Microcontroller Based Temperature Control System with Real Time Data Logger. International Journal of Advance Research in Computer Science and Management Studies. Vol.2, Issue.11, page: 51-57. (2014).

\section{Figure captions}

Figure 1. Rule based reasoning method to control a LM35DZ as temperature sensor and/or PIR sensor to detect a motion to trigger a buzzer in order to solving a room security issue.

Figure 2. The inference engine that utilize forward chaining is used on security system is as an electronic access control.

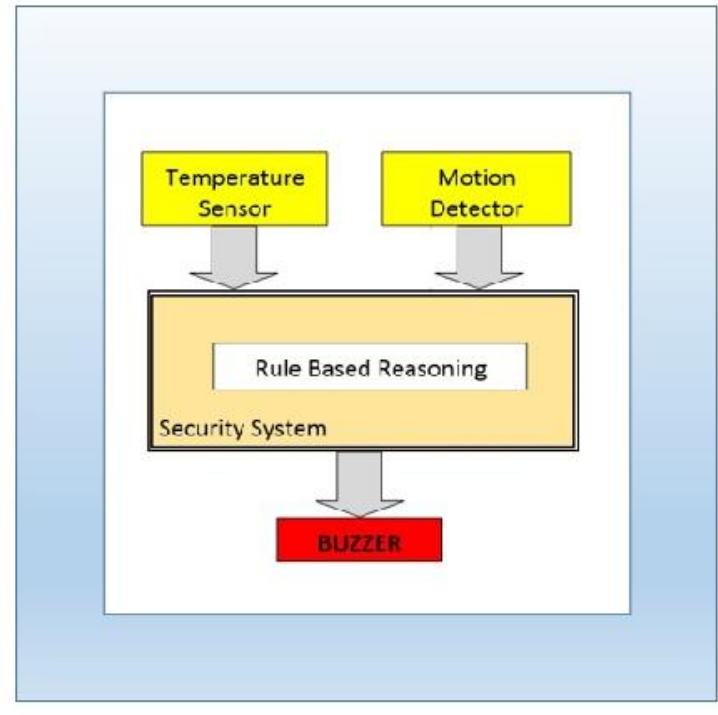

Figure 1. Mufadhol, et al.

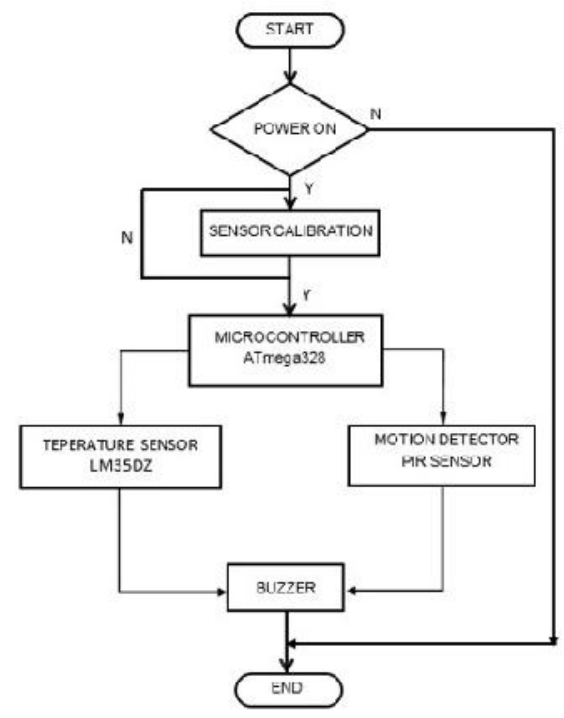

Figure 2. Mufadhol, et al. 